\section{THU0299 MYOCARDIAL INVOLVEMENT IN TAKAYASU ARTERITIS PATIENTS ASSESSED BY MAGNETIC RESONANCE IMAGING AND ITS RELATION WITH DISEASE ACTIVITY}

A. Chattopadhyay ${ }^{1}$, M. Singhal ${ }^{2}$, U. Debi ${ }^{2}$, A. Sharma ${ }^{1}$, S. Jain ${ }^{1} .{ }^{1} P G I M E R$, Chandigarh, Clinical Immunology \& Rheumatology Services, Department of Internal Medicine, Chandigarh, India; ${ }^{2} P G I M E R$ Chandigarh, Department of Radiodaignosis, Chandigarh, India

Background: Cardiac involvement in Takayasu arteritis $(\mathrm{TA})$ is the major cause of morbidity and mortality. [1] Cardiovascular magnetic resonance (CMR) is an excellent modality for the assessment of myocardial involvement. Studies have shown subclinical myocardial scarring in $25-27 \%$ of patients.[2,3] There is no such study from India.

Objectives: To evaluate the prevalence of myocardial involvement in TA, as detected by CMR and its correlation with disease activity score (ITAS 2010 and ITAS-A).

Methods: Patients classified as Takayasu arteritis according to Sharma et al. criteria [4] were included after an informed consent. Demographic, clinical, laboratory data were documented in the predesigned proforma. CMR was done on a dedicated CMR machine. Disease activity was recorded by ITAS2010 and ITAS-A.[5] Ethical clearance has been obtained from the ethics committee of the institute (INT/IEC/2018/001538).

Results: In the present study, 37 TA patients were included. Mean( \pm SD) age was $29 \pm 11$ years. Female to male ratio was 3:1. The most frequent presenting symptom was upper limb claudication (49\%), and vessel involved was left subclavian and descending thoracic aorta(75\% each). Of the total cohort, $65 \%$ had hypertension, $35 \%$ had dyslipidemia and $19 \%$ had valvular involvement. Five patients (14\%) had myocardial involvement as detected by CMR. Three (8\%) patients had late gadolinium enhancement(LGE) on CMR suggestive of myocardial fibrosis. In the current study, both the CMR and echocardiography performed equally in detecting various valvular heart disease, whereas only CMR had detected subclinical myocardial fibrosis in two patients. Details of different risk factors and relation with disease activity provided in table 1.

Conclusion: To the best of our knowledge, this is the largest cohort on CMR in TA. Prevalence of subclinical myocardial involvement in Indian patients was much less $(8 \%$ vs $25-27 \%$ ) compared to the previous studies. The higher percentage of LGE detected by the earlier studies may be a reflection of cumulative damage with increasing age, prolonged hypertension, and disease duration. Myocardial involvement trend towards early age of onset, less disease duration, lack of classical risk factors, and more with disease activity. Judicious use of CMR may help in detecting subclinical myocardial involvement.

Table 1. Relation of different risk factors with myocardial heart disease.

\begin{tabular}{|c|c|c|c|}
\hline Parameters & MHD - $(n=32)$ & $M H D+(n=5)$ & $\mathrm{p}$ \\
\hline Disease duration $>5 \mathrm{yr}$ & $13(41)$ & $2(40)$ & 0.98 \\
\hline Age at onset $<18 \mathrm{yr}$ & $7(22)$ & $3(60)$ & 0.07 \\
\hline $\mathrm{BMl}>23 \mathrm{~kg} / \mathrm{m}^{2}$ & $19(59)$ & $1(20)$ & 0.1 \\
\hline $\mathrm{Hb}<12 \mathrm{gm} / \mathrm{dl}$ & $16(50)$ & $2(40)$ & 0.68 \\
\hline Platelets $>450 \times 10^{9} / \mathrm{L}$ & $4(13)$ & $0(0)$ & 0.40 \\
\hline $\mathrm{ESR}>20 \mathrm{~mm}$ in $1^{\text {st }}$ hour & $28(88)$ & $4(80)$ & 0.65 \\
\hline CRP $>10 \mathrm{mg} / \mathrm{dl}$ & $16(50)$ & $4(80)$ & 0.21 \\
\hline Cholesterol>200 mg/dl & $10(31)$ & $1(20)$ & 0.61 \\
\hline LDL>130 mg/dl & $9(28)$ & $0(0)$ & 0.17 \\
\hline BNP>125 pg/ml & $11(34)$ & $3(60)$ & 0.27 \\
\hline ITAS2010-Active & $17(53)$ & $3(60)$ & 0.77 \\
\hline ITAS-A-Active & $11(34)$ & $3(60)$ & 0.27 \\
\hline
\end{tabular}

[MHD: myocardial heart disease]

\section{References:}

[1] Cong XL, Dai SM, Feng $X$ et al. Takayasu's arteritis: clinical features and out- comes of 125 patients in China. Clin Rheumatol 2010;29:973-81.

[2] Keenan NG, Mason JC, Maceira A et al. Integrated cardiac and vascular assessment in Takayasu arteritis by cardiovascular magnetic resonance. Arthritis Rheum. 2009;60:3501-9.

[3] Comarmond C, Cluzel P, Toledano D et. al. Findings of cardiac magnetic resonance imaging in asymptomatic myocardial ischemic disease in Takayasu arteritis. Am J Cardiol. 2014;113:881-7.
[4] Sharma BK, Jain S, Suri S et al. Diagnostic criteria for Takayasu Arteritis. Int J Cardiol 1996;54: S141-7.

[5] Misra R, Danda D, Rajappa SM, et al. Development and initial validation of the Indian Takayasu Clinical Activity Score (ITAS2010). Rheumatology 2013;52:1795-801.

Disclosure of Interests: None declared

DOI: 10.1136/annrheumdis-2020-eular.2073

\section{THU0300 RISK FACTORS FOR COMPLICATIONS AND REFRACTORY COURSE IN PATIENTS WITH ANCA-ASSOCIATED SYSTEMIC VASCULITIS}

A. Chudinov ${ }^{1}$, I. Belyaeva ${ }^{2}$, M. Pervakova ${ }^{3}$, V. Mazurov ${ }^{2}$, O. Inamova ${ }^{1}$, S. Lapin ${ }^{3}$. ${ }^{1}$ Clinical Rheumatological Hospital № 25, Saint-Petersburg, Russian Federation; ${ }^{2}$ North-West State Medical University named after I.I. Mechnikov, Saint-Petersburg, Russian Federation; ${ }^{3}$ First Pavlov State Medical University of St. Petersburg, Saint-Petersburg, Russian Federation

Background: ANCA-associated systemic vasculitis (AAV) is characterized by a high incidence of complications and high mortality. The most significant complications during the first 3 years of the disease are infectious and cardiovascular. Development of chronic kidney disease also impairs the prognosis of AAV. Refractory to induction therapy can significantly increase the severity of organ lesions in patients with AAV.

Objectives: The aim of this study was to determine risk factors for complications and refractory course in patients with AAV.

Methods: Patients with granulomatosis with polyangiitis (GPA), microscopic polyangiitis (MPA) and eosinophilic granulomatosis with polyangiitis (EGPA) were observed during the first 3 years of the disease and included in this study between 2010 and 2018. Most common infectious complications requiring inpatient treatment were pneumonia, mycosis, sepsis, purulent arthritis, purulent otitis media. Cardiovascular complications included pulmonary thromboembolism, myocardial infarction, ischemic stroke, venous thrombosis.

Results: In total 209 (165 [79\%] female and mean age $51.8 \pm 13.2$ years) AAV patients (94 GPA; $46 \mathrm{MPA}$; and 69 EGPA) were included in the analysis. Risk factors for infectious complications were BVAS level at the beginning of induction therapy $>25(\mathrm{OR}-2.92,95 \% \mathrm{Cl}(1.53 ; 5.45) \mathrm{p}<0.001)$, usage of prednisone in doses more than $60 \mathrm{mg} /$ day at the induction of remission (OR $-2.76,95 \% \mathrm{Cl}(1.45 ; 5.29) \mathrm{p}=0.003)$, usage of prednisone in doses $\geq 10 \mathrm{mg}$ / day after 6 months of induction therapy (OR $-2.60,95 \% \mathrm{Cl}(1.38 ; 4.93)$ $\mathrm{p}=0.003$ ), ANCA-PR3 positivity (OR $-2.25,95 \% \mathrm{Cl}(1.13 ; 4.46) \mathrm{p}=0.017)$ and presence of diabetes mellitus in the AAV onset (OR $-1.77,95 \% \mathrm{Cl}$ $(1.14 ; 3.45) \mathrm{p}=0.038)$. Patients with AAV had following risk factors for cardiovascular complications: male (OR $-2.28,95 \% \mathrm{Cl}(1.33 ; 3.88) \mathrm{p}=0.002)$, BVAS level $>25(\mathrm{OR}-2.1,95 \% \mathrm{Cl}(1.11 ; 3.16) \mathrm{p}=0.008)$ and presence of coronary artery disease in the AAV onset $(\mathrm{OR}-2.2,95 \% \mathrm{Cl}(1.18 ; 4.10)$ $\mathrm{p}=0.015)$. ANCA positivity $(\mathrm{OR}-5.62,95 \% \mathrm{Cl}(2.1 ; 14.9) \mathrm{p}<0.001)$, presence of rapidly progressive glomerulonephritis in the first 3 months from onset AAV $(O R-5.02,95 \% \mathrm{Cl}(3.42 ; 7.35) \mathrm{p}<0.001)$ and over 60 years of age $(\mathrm{OR}-2.17,95 \% \mathrm{Cl}(1.38 ; 3.44) \mathrm{p}=0.001)$ were risk factors of development of chronic kidney disease. Risk factors for refractory to induction therapy in patients with AAV were ANCA-PR3 positivity (OR - 3.13, 95\% Cl $(1.63 ; 6.02)$ $p<0.001)$, BVAS level $>25(\mathrm{OR}-2.63,95 \% \mathrm{Cl}(1.74 ; 4.34) \mathrm{p}<0.001)$, initiation of therapy after 4 months from the onset of clinical manifestations $(\mathrm{OR}-2.17$, $95 \% \mathrm{Cl}(1.26 ; 3.91) \mathrm{p}=0.005)$. We additionally defined that identification of pathological phenotypes of alpha-1-antitrypsin was risk factors for refractory course in patients with GPA manifestations (OR $-2.66,95 \% \mathrm{CI}(1.12 ; 6.33)$ $\mathrm{p}=0.048$ ).

Conclusion: Our study has shown that high disease activity, ANCA positivity and comorbid pathology increase risk of serious complications. Early administration of immunosuppressive therapy, adequate steroid dosing and use of risk factors for complications and refractory course in clinical practice can significantly improve the prognosis of AAV.

Disclosure of Interests: None declared DOI: 10.1136/annrheumdis-2020-eular.6460 